\title{
Efektivitas Model Pembelajaran Missouri Mathematics Project untuk Meningkatkan Hasil Belajar Siswa SMA
}

\author{
Arief A Rahman ${ }^{*}$ dan Cut E Nasryah ${ }^{2}$ \\ ${ }^{1 *}$ Program Studi Pendidikan Matematika, STKIP Bina Bangsa Meulaboh \\ ${ }^{2}$ Program Studi Pendidikan Guru Sekolah Dasar, STKIP Bina Bangsa Meulaboh \\ Jalan Nasional Meulaboh-Tapaktuan, Meulaboh, Aceh Barat, Indonesia \\ 1*sirariefaulia@gmail.com, 2cut.evanasryah11@gmail.com
}

Artikel diterima: 09-12-2019, direvisi: 27-05-2020, diterbitkan: 31-05-2020

\begin{abstract}
Abstrak
Pembelajaran yang tidak kondusif membuat siswa menjadi sasaran pembelajaran yang pasif, dan hanya menerima konsep dari guru. Penelitian ini bertujuan untuk mendeskripsikan efektivitas penerapan model MMP dalam meningkatkan hasil belajar pada materi sistem persamaan linear dua variabel (SPLDV) pada siswa kelas X SMAN 1 Kuala Kabupaten Nagan Raya. Waktu penelitian dilaksanakan pada semester ganjil tahun ajaran 2017/2018 di SMAN 1 Kuala Kabupaten Nagan Raya. subjek penelitian ini adalah X Mia ${ }_{1}$ SMAN 1 Kuala dengan jumlah 20 siswa. Instrumen yang digunakan dalam penelitian terdiri dari tes. Teknik analisis data menggunakan analisis deskriptif. Hasil Penelitian menunjukan bahwa penerapan model pembelajaran MMP efektif pada materi SPLDV dan dapat dilihat dari hasil tes dengan nilai rata-rata uji coba I dan II masing-masing 60,2 dan 74,1. Hasil tersebut menunjukkan secara keseluruhan siswa tuntas belajar karena nilai rata-rata sebesar 74,1 dan memenuhi KKM yang diterapkan yaitu 70 .

Kata Kunci: Efektivitas, Hasil Belajar, Missouri Mathematics Project, analisis deskriptif, siswa SMA.

\section{The Effectiveness of the Missouri Mathematics Project Learning Model for Improving High School Student Learning Outcomes}

\begin{abstract}
Non-conducive learning makes students passive learning targets, and only accepts concepts from the teacher. This study aims to describe the effectiveness of the application of the MMP model in improving learning outcomes in the material system of two-variable linear equations (SPLDV) in class $X$ students of SMAN 1 Kuala, Nagan Raya Regency. When the research was conducted in the odd semester of the academic year 2017/2018 at SMAN 1 Kuala Nagan Raya Regency. The subject of this research is X Mia1 SMAN 1 Kuala with a total of 20 students. The instrument used in the study consisted of tests. Data analysis techniques using descriptive analysis. The results showed that the application of the MMP learning model was effective in the SPLDV material and could be seen from the results of the tests with an average score of trials I and II respectively 60.2 and 74.1. These results indicate overall students have finished learning because the average value of 74.1 and meet the applied KKM is 70 .

Keywords: Effectiveness, Learning Outcomes, Missouri Mathematics Project, descriptive analysis, high school students.
\end{abstract}




\section{Pendahuluan}

Kualitas sumber daya manusia ditentukan berdasarkan peran aktif Pendidikan sebagai modal awal pembangunan (Sudarsana, 2016; Wijaya, et al, 2016; Pamungkas \& Afriansyah, 2017; Erin \& Maharani, 2018), ditambah dengan era globalisasi yang menuntut generasi muda untuk terus bersaing dan meningkatkan kompetensi diri termasuk meningkatkan kemampuan dalam matematika, karena matematika penting dalam kehidupan manusia dan diperlukan sebagai alat dalam pengembangan teknologi dan industry (Nanang, 2012; Murtiyasa, 2016). Matematika mampu melatih kemampuan berfikir dan kemampuan memecahkan masalah seharihari (Nawi, 2012; Afriansyah, 2016; Lestari \& Rosdiana, 2018).

Namun, gambaran tentang pembelajaran matematika yang diterapkan selama ini masih abstrak dan siap pakai (Anugraha, 2012; Lisnani \& Asmaruddin, 2018). Guru hanya memberikan konsep dan aplikasinya sehingga siswa menjadi pasif dan pembelajaran tidak bermakna (Nasryah \& Rahman, 2018; Ridia \& Afriansyah, 2019). Pembelajaran berpusat kepada guru dan siswa menjadi pasif. Metode konvensional yang diterapkan membuat pembelajaran menjadi monoton (Winarti \& Haq, 2013; Rahman \& Fauziana, 2018). Pembelajaran yang diterapkan hanya melatih siswa menghafal rumus, tanpa mengetahui dari mana konsep tersebut diperoleh (Mubarok \& Nanang, 2013).

Pembelajaran yang demikian tidak kondusif sehingga membuat siswa menjadi sasaran pembelajaran yang pasif, dan hanya menerima konsep dari guru (Budianto, 2018; Faturohman \& Afriansyah, 2020). Hal ini berimplikasi pada efektif dan efisien serta menyiapkan peserta didik agar dapat menggunakan matematika dan pola pikir matematika dalam kehidupan sehari-hari dalam mempelajari berbagai ilmu pengetahuan atau tidak sesuai dengan target yang ingin dicapai dalam suatu proses pembelajaran (Sundayana, 2012; Ruswana \& Zamnah, 2018; Budiarti \& Lestariningsih, 2018).

Alternatif model pembelajaran yang diprediksi dapat meningkatkan proses pembelajaran menjadi lebih efektif salah satunya adalah penerapan dengan model MMP (Haloho, 2016) yaitu salah satu model pembelajaran yang terstruktur dengan pengembangan ide dan perluasan konsep matematika dengan disertai adanya latihan soal baik itu berkelompok maupun individu serta perpaduan antara aktivitas guru dan aktivitas (Latifah \& Madio, 2014; Kurniasari \& Susanto, 2015; Yantri, 2017; Rahman, 2018). Pada model pembelajaran MMP ini siswa diberikan kesempatan juga keleluasaan untuk berpikir secara berkelompok dalam menyelesaikan permasalahan yang diberikan oleh guru berkaitan dengan materi pembelajaran (Purwanti, 2015; Nurmayanti, et, al, 2019). 
Menurut kamus Bahasa InggrisIndonesia efektivitas berasal dari kata "effective" yang artinya "berhasil" atau "ditaati", sedangkan menurut Hamdani (2011) cara mengukur efektivitas adalah menentukan transferbilitas (kemampuan memindahkan) prinsip-prinsip yang dipelajari (Suryati, et, al, 2016; Rukayah, 2012). Kalau tujuan dapat dicapai dalam waktu yang lebih singkat dengan strategi tertentu daripada strategi yang lain, strategi itu lebih efektif jika kemampuan mentransfer informasi atau skiil yang dipelajari lebih besar dicapai melalui strategi tertentu dibandingkan dengan strategi yang lain, strategi tersebut lebih efektif untuk mencapai tujuan.

Efektivitas pembelajaran menggunakan model pembelajaran MMP yaitu ukuran keberhasian dari suatu proses interaksi antar siswa maupun siswa dengan guru dalam situasi edukatif untuk mencapai tujuan pembelajaran melalui hasil belajar siswa (Nopendra, 2017).

Kelebihan dan kekurangan model pembelajaran pembelajaran Missouri Mathematics Project memiliki beberapa kelebihan, diantaranya (Dewi, 2013; Nurjannah, 2019) Banyak materi yang bisa tersampaikan kepada peserta didik karena tidak terlalu banyak memakan waktu. Artinya, penggunaan waktu dapat diatur relatif ketat. 2) Banyak latihan sehingga peserta didik mudah terampil dengan beragan soal. Di samping memiliki kelebihan, model pemebelajaran Missouri Mathematics Project juga memiliki kekurangan, diantaranya (Dewi, 2013; Nurjannah, 2019) Kurang menempatkan peserta didik pada posisi yang aktif. 2) Mungkin peserta didik akan cepat bosan karena lebih banyak mendengar. Meskipun dalam model pembelajaran Missouri Mathematics Project ini terdapat beberapa kekurangan, namun kekurangan tersebut dapat diatasi dengan cara: 1) Memberikan kesempatan kepada siswa untuk menanyakan hal-hal yang mereka anggap sulit atau kurang bahkan tidak dipahami. 2) Memperbanyak latihan soal sehingga siswa mudah terampil mengerjakan beragam soal. 3) Memberikan bimbingan kepada siswa yang masih mengalami kesulitan.

\section{Metode}

Tujuan penelitian ini adalah untuk mendeskripsikan efektivitas penerapan Missouri Mathematics Project pada materi sistem persamaan linear dua variabel, pendekatan yang digunakan dalam penelitian ini adalah pendekatan kuantitatif. Penelitian deskriptif (descriptive research) adalah suatu penelitian ditujukan untuk mengambarkan suatu fenomena-fenomena apa adanya, yang berlangsung pada saat ini atau pada saat yang lampau (Hamdi \& Bahruddin, 2015).

Penelitian ini dilaksanakan di SMA Negeri 1 Kuala, Kabupaten Nagan Raya. subjek dalam penelitian ini adalah siswa $X_{\text {Mia } 1}$ SMA Negeri 1 Kuala. 
Instrumen yang digunakan dalam penelitian ini Tes. Tes adalah serentan pertanyaan atau latihan serta alat yang lain digunakan untuk mengukur keterampilan, pengetahuan intelegensi, kemampuan atau bakat yang dimiliki oleh individu atau kelompok (Lubis, 2019). Lembar soal tes dalam penelitian ini berbentuk essay dengan jumlah soal 4 butir. Tes diambil dari buku pegangan guru matematika kelas X kurikulum 2013 yang disesuaikan dengan menggunakan model MMP.

Data dalam penelitian ini adalah data kuantitatif yaitu nilai siswa dari hasil tes pada materi sistem persamaan linear dua variabel. Setelah semua data terkumpul maka dideskripsikan dan dianalisis menggunakan rumus:

$\mathrm{M}_{\mathrm{x}}=\frac{\sum \mathrm{X}}{\mathrm{N}}$

Mx : Mean (Rata-rata)

$\sum X$ : Jumlah nilai ke-i

$N$ : Banyaknya nilai

Setelah peneliti melakukan perhitungan, selanjutnya peneliti kategorikan tingkat ketuntasan hasil belajar Matematika siswa yang diperoleh dari hasil tes, dengan kategori ketuntasan adalah:

Tabel 1.

Kategori Ketuntasan Hasil Belajar Siswa

\begin{tabular}{ccc}
\hline KKM & Nilai & Predikat \\
\hline \multirow{3}{*}{70} & $91-100$ & Sangat Baik (A) \\
\cline { 2 - 3 } & $81-90$ & Baik (B) \\
\cline { 2 - 3 } & $70-80$ & Cukup (C) \\
\cline { 2 - 3 } & $<70$ & Kurang (D) \\
\hline
\end{tabular}

\section{Hasil dan Pembahasan}

Subjek dalam penelitian ini adalah siswa kelas $X_{\text {Mia1 }}$ SMA Negeri 1 Kuala yang berjumlah 20 siswa. Dalam peneltian ini dilakukan dua tahap yaitu validasi dan penerapan model MMP dengan langkah sintaksnya, yaitu: (1) review, (2) pengembangan, (3) latihan dengan bimbingan, (4) kerja mandiri dan (5) penugasan yang di akhiri dengan pemberian soal tes. Pemberian soal tes dilakukan untuk mengukur pemahaman siswa akan materi sistem persamaan linear dua variabel. Peneliti merancang tindakan yang akan dilakukan pada proses pembelajaran matematika, melalui tahapan berikut:

1) Merancang RPP berdasarkan materi sistem persamaan linear dua variabel yang akan diajarkan dan memuat serangkaian kegiatan dengan menggunakan model MMP.

2) Mempersiapkan soal tes di akhir pertemuan.

Adapun kegiatan yang dilaksanakan terdiri dari kegiatan awal, kegiatan inti, dan kegiatan akhir.

a) Kegiatan Awal

Kegiatan awal berisi tentang kegiatan rutin seperti pembukaan (salam), berdoa, mengecek kehadiran siswa, dan menyampaikan tujuan pembelajaran yang akan dicapai yaitu menentukan penyelesaian dari sistem persamaan liner dua variabel 
b) Kegiatan Inti

Pada kegiatan ini, guru melakukan proses pembelajaran dengan menggunakan model MMP. kemudian guru mengadakan tanya jawab dengan siswa mengenai konsep sistem persamaan linear dua variabel, selanjutnya membagi siswa menjadi empat kelompok. Setiap kelompok terdiri dari lima siswa baik lakilaki maupun perempuan dengan tingkat kemampuan yang berbeda-beda. Selanjutnya masing-masing kelompok diberi lembar kerja siswa (LKS) untuk dikerjakan secara berkelompok.

Setelah masing-masing kelompok mendapatkan LKS, maka Guru menjelaskan tata cara pengerjaannya kepada siswa agar dapat diselesaikan Bersama kelompok sesuai dengan instruksi. Setelah selesai dikerjakan, hasil yang didapat dipresentasikan oleh perwakilan kelompok dan diperhatikan dan disaksikan oleh kelompok yang lain.

Lalu kelompok yang memiliki pendapat yang berbeda atau memiliki sanggahan maka dapat mengajukan diri ketika sesi diskusi dibuka setelah presentasi. Guru sebagai fasilitator membahas dan mengarahkan proses diskusi siswa agar materi diskusi terarah. Selama proses diskusi dan presentasi, guru memberikan penghargaan kepada siswa dan kelompok yang telah berhasil mengerjakan tugas dengan baik. Penghargaan yang diberikan oleh guru dalam bentuk verbal maupun non verbal.

\section{c) Penutup}

Kegiatan presentasi dan diskusi diakhiri dengan penarikan kesimpulan oleh masing-masing kelompok dan materi yang sudah dipelajari secara bersama-sama. Guru juga memberikan kesempatan kepada siswa untuk bertanya jika ada halhal yang kurang jelas atau belum dipahami. Guru juga melakukan tindak lanjut dengan berpesan kepada siswa untuk mengulang pelajaran di rumah dan rajin belajar agar dapat memperoleh hasil yang baik. Semua kegiatan sudah dijalankan, kegiatan yang terakhir guru menutup pelajaran dengan mengucap salam kepada siswa.

Pada akhir tindakan ini dilakukan evaluasi belajar siswa yaitu pemberian soal tes untuk melihat tingkat keefektifan model MMP terhadap pencapaian hasil belajar siswa. Pengukuran hasil belajar siswa dilakukan dengan memberikan soalsoal tes secara individu kepada siswa.

Pelaksanaan tes dilakukan satu kali dengan waktu 75 menit. Nilai yang diperoleh dari hasil tes terhadap 20 orang siswa kelas X SMA Negeri 1 Kuala. Hasil tes yang diberikan dapat dilihat dalam gambar berikut ini:

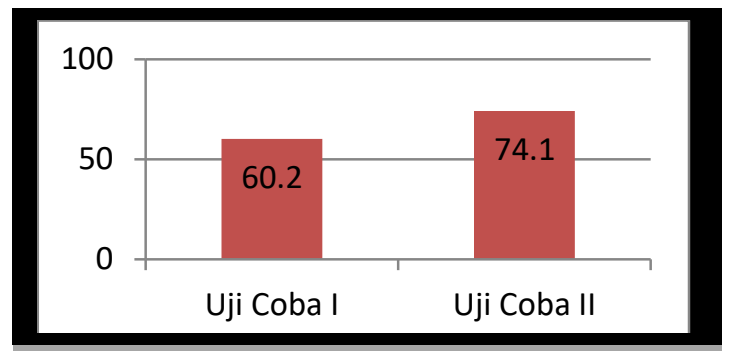

Gambar 1. Hasil Tes Siswa. 
Setelah diterapkan model MMP nilai tertinggi siswa 90 dan nilai terendah 65. Diperoleh hasil belajar siswa dengan nilai rata-rata pada uji coba I adalah 60,2 dan tuntas pada Uji Coba II yaitu 74,1. Hasil tersebut menunjukkan secara keseluruhan siswa tuntas belajar karena nilai rata-rata.

Berdasarkan hasil tes siswa dapat disimpulkan bahwa setelah diterapkan model MMP nilai tertinggi siswa 90 dan nilai terendah 65. Diperoleh hasil belajar siswa dengan nilai rata-rata adalah 74,1. Hasil tersebut menunjukkan secara keseluruhan siswa tuntas belajar karena nilai rata-rata sebesar 74,1 dan memenuhi KKM yang diterapkan yaitu 70 kategori ketuntasan hasil belajar siswa dapat dilihat pada Tabel 2 berikut:

Tabel 2.

\begin{tabular}{|cccc|}
\multicolumn{3}{c}{ Ketuntasan Hasil Belajar Siswa Uji Coba II } \\
\hline KKM & Nilai & Predikat & $\begin{array}{c}\text { Jumlah } \\
\text { siswa }\end{array}$ \\
\hline \multirow{3}{*}{70} & $91-100$ & Sangat Baik (A) & - \\
\cline { 2 - 4 } & $81-90$ & Baik (B) & 3 \\
\cline { 2 - 4 } & $70-80$ & Cukup (C) & 13 \\
\cline { 2 - 4 } & $<70$ & Kurang (D) & 4 \\
\hline Total Siswa & & 20
\end{tabular}

Tidak ada siswa yang memperoleh nilai 91-100 dari KKM 70 dengan predikat Sangat Baik (A), sedangkan siswa yang memperoleh nilai 81-90 dari KKM 70 dengan predikat Baik (B) ada 3 siswa dari 20 siswa, dan siswa yang memperoleh nilai 70-80 dari KKM 70 dengan predikat Cukup (C) ada 13 siswa dari 20 siswa, serta siswa yang memperoleh nilai $<70$ dari KKM 70 dengan predikat Kurang (D) ada 4 siswa dari 20 siswa.

Melengkapi data mengenai respon terhadap model MMP pada materi sistem persamaan linear dua variabel peneliti memberi angket respon siswa yang diisi oleh 20 orang siswa. Hasil angket siswa terhadap kegiatan belajar mengajar dengan menerapkan model MMP pada materi sistem persamaan linear dua variabel mendapat respon positif dari siswa.

Respon siswa diperoleh dengan menggunakan angket siswa yang diberikan pada akhir pertemuan setelah proses pembelajaran selesai. Berdasarkan hasil angket siswa yang diisi oleh 20 orang siswa dengan dengan butir-butir pertanyaan mengenai pembelajaran matematika materi sistem persamaan linear dua variabel menggunakan model MMP butirbutir pertanyaan angket dapat dilihat sebagai berikut:

Tabel 3. Hasil Angket Siswa

\begin{tabular}{|c|c|c|c|}
\hline No & Butir Pertanyaan-Pertanyaan & Respon & $F$ \\
\hline \multirow[t]{2}{*}{1} & \multirow{2}{*}{$\begin{array}{l}\text { Apakah anda merasa senang } \\
\text { dengan penerapan model MMP } \\
\text { pada materi sistem persamaan } \\
\text { linear dua variabel? }\end{array}$} & Ya & 20 \\
\hline & & Tidak & 0 \\
\hline \multirow[t]{3}{*}{2} & \multirow{3}{*}{$\begin{array}{lrr}\text { Apakah dengan penerapan } & \text { model } \\
\text { MMP pada materi } & \text { sistem } \\
\text { persamaan linear dua variabel } & \text { sangat membantu } & \text { dalam } \\
\text { memahami materi } & \text { yang } \\
\text { disampaikan? } & & \\
\end{array}$} & Ya & 20 \\
\hline & & & \\
\hline & & Tidak & 0 \\
\hline \multirow[t]{3}{*}{3} & \multirow{3}{*}{$\begin{array}{l}\text { Apakah dengan mengunakan } \\
\text { penerapan model MMP dapat } \\
\text { menimbulkan rasa ingin tahu yang } \\
\text { tinggi di pelajaran matematika } \\
\text { materi sistem persamaan linear } \\
\text { dua variabel? }\end{array}$} & Ya & 19 \\
\hline & & & \\
\hline & & Tidak & 1 \\
\hline \multirow[t]{2}{*}{4} & \multirow{2}{*}{$\begin{array}{l}\text { Apakah pembelajaran matematika } \\
\text { materi sistem persamaan linear } \\
\text { dua variabel menggunakan model }\end{array}$} & $\mathrm{Ya}$ & 20 \\
\hline & & Tidak & 0 \\
\hline
\end{tabular}

Mosharafa: Jumal Pendidikan Matematika Volume 9, Nomor 2, Mei 2020 Copyright $\odot 2020$ Mosharafa: Jurnal Pendidikan Matematika 


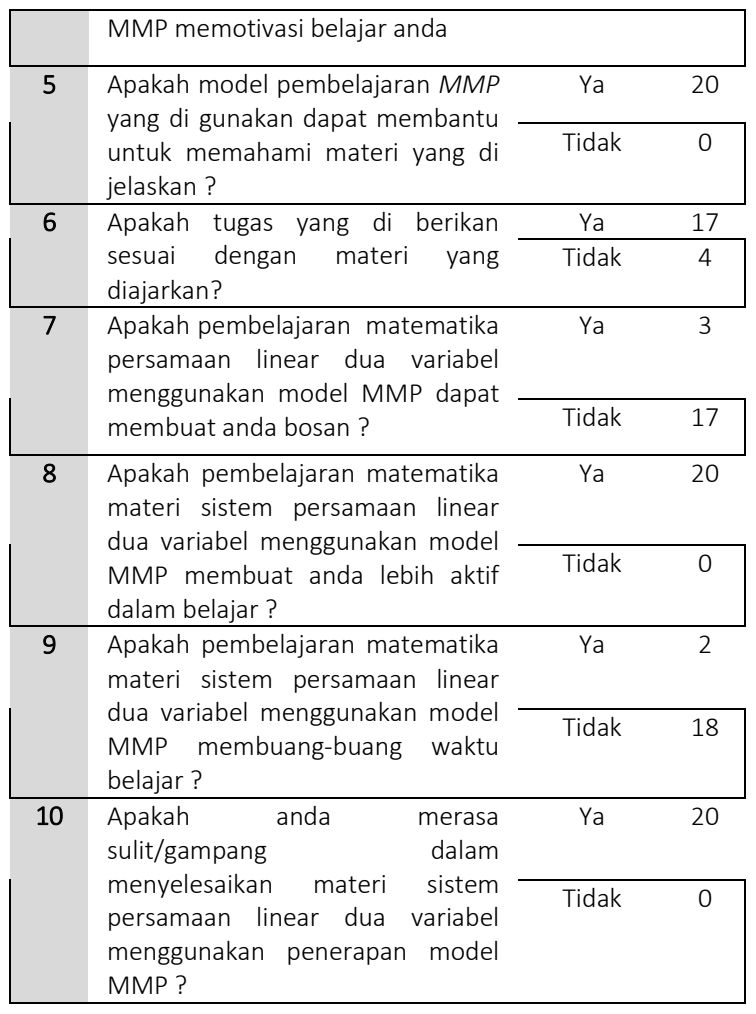

Hasil angket dalam penerapan model MMP pada materi sistem persamaan linear dua variabel mendapat respon positif dari siswa, dimana pada pertanyaan butir no 1 dan no 7 siswa merasa senang dengan penerapan model MMP pada materi sistem persamaan linear dua variabel dan tidak membuat siswa bosan, sedangkan pada pertanyaan no 2 dan butir pertanyaan no 5 dimana siswa dengan penerapan model MMP pada materi sistem persamaan linear dua variabel sangat membantu dalam memahami materi yang disampaikan.

Hasil angket pada butir pertanyaan no 3 dimana pembelajaran dengan mengunakan penerapan model MMP dapat menimbulkan rasa ingin tahu siswa yang tinggi di pelajaran matematika materi sistem persamaan linear dua variabel ini terlihat dengan respon siswa dengan menjawab 95\% menjawab ya dan 5\% menjawab tidak, sedangkan pada butir pertanyaan no 4 dimana pembelajaran matematika materi sistem persamaan linear dua variabel menggunakan model MMP dapat memotivasi belajar siswa dengan respon siswa $100 \%$ menjawab ya.

Butir pertanyaan no 6 dimana tugas yang di berikan sesuai dengan materi yang diajarkan mendapat respon dari siswa dengan menjawab ya $85 \%$ dan yang menjawab tidak ada 15\%, sedangkan pada butir pertanyaan no 8 dimana pembelajaran matematika materi sistem persamaan linear dua variabel menggunakan model MMP membuat anda lebih aktif dalam belajar mendapat respon dari siswa dengan menjawab ya ada $100 \%$.

Hasil angket dalam penerapan model MMP pada materi sistem persamaan linear dua variabel mendapat respon positif dari siswa, dimana pembelajaran matematika materi sistem persamaan linear dua variabel menggunakan model MMP membuang-buang waktu belajar pada pertanyaan butir no 9 mendapat respon dari siswa dengan menjawab ya $10 \%$ dan yang menjawab tidak ada $90 \%$, sedangkan pada butir pertanyaan no 10 dengan butir pertanyaan apakah anda merasa sulit/gampang dalam menyelesaikan materi sistem persamaan linear dua variabel menggunakan penerapan model MMP dimana mendapat 
respon dari siswa dengan menjawab ya $100 \%$ dan yang menjawab tidak ada $0 \%$.

Berdasarkan respon siswa terhadap angket yang diberikan kepada siswa kelas $X_{\text {Mia1 }}$ SMA Negeri 1 Kuala dalam penerapan model MMP pada materi sistem persamaan linear dua variabel respon siswa dapat di dapat kelompokan sebagai sebagai berikut:

Tabel 4.

Persentase Hasil Angket Siswa

\begin{tabular}{cccc}
\hline No & $\begin{array}{c}\text { Alternatif } \\
\text { Responden }\end{array}$ & Frekuensi & Persentase \\
\hline 1 & Ya & 14 & $70 \%$ \\
\hline 2 & Tidak & 6 & $30 \%$ \\
\hline
\end{tabular}

Hasil angket dalam penerapan model MMP pada materi sistem persamaan linear dua variabel mendapat respon positif dari 14 orang dengan persentase sebesar $70 \%$, sedangkan 6 tidak mendapat respon positif dari siswa dengan persentase $30 \%$.

Berdasarkan hasil angket yang dibagikan kepada perserta didik dapat diperoleh dengan menerapkan model MMP dapat membantu dalam siswa memahami materi yang disampaikan, pembelajaran matematika materi sistem persamaan linear dua variabel menggunakan model MMP membuat siswa lebih aktif dalam belajar, dan dapat di simpulkan bahwa MMP efektif pada materi sistem persamaan linear dua variabel termasuk dalam kategori baik, hal ini dapat dilihat dari hasil pengamatan 70\% siswa menyatakan ya, sedangkan yang menyatakan tidak $30 \%$ pada model
MMP dapat efektif pada materi sistem persamaan linear dua variabel.

Dimana dengan penerapan model MMP pada materi sistem persamaan linear dua variabel membantu siswa dalam memahami materi yang disampaikan, dalam pembelajaran matematika persamaan linear dua variabel menggunakan model MMP tidak membuat siswa menjadi bosan, serta siswa lebih aktif dalam belajar.

\section{Penutup}

Berdasarkan hasil penelitian yang dilakukan di SMA Negeri 1 Kuala tentang efektivitas penerapan model MMP dengan materi pembelajaran sistem persamaan linear dua variabel dapat disimpulkan bahwa melalui penerapan model MMP pada kelas $X_{\text {MIA1 }}$ di SMA Negeri 1 Kuala dapat disimpulkan bahwa tidak ada siswa yang memperoleh nilai 91-100 dari KKM 70 dengan predikat Sangat Baik (A), sedangkan siswa yang memperoleh nilai 81-90 dari KKM 70 dengan predikat Baik (B) ada 3 siswa dari 20 siswa, dan siswa yang memperoleh nilai 70-80 dari KKM 70 dengan predikat Cukup (C) ada 13 siswa dari 20 siswa, serta siswa yang memperoleh nilai $<70$ dari KKM 70 dengan predikat Kurang (D) ada 4 siswa dari 20 siswa, dan tidak ada syarat tertentu untuk siswa mengikuti proses pembelajaran yang menggunakan model MMP.

Pembelajaran dengan model MMP efektif pada materi sistem persamaan linear dua variabel di kelas $\mathrm{X}_{\text {MIA1 }}$ di SMA 
Negeri 1 Kuala setelah diterapkan model MMP dapat dilihat dari hasil tes siswa dengan nilai tertinggi siswa 90 dan nilai terendah 65. Diperoleh hasil belajar siswa dengan nilai rata-rata adalah 74,1.

Hasil tersebut menunjukkan secara keseluruhan siswa tuntas belajar karena nilai rata-rata sebesar 74,1 dan memenuhi KKM yang diterapkan yaitu 70 serta hasil angket siswa terhadap kegiatan belajar mengajar dengan menerapkan model MMP pada materi sistem persamaan linear dua variabel mendapat repon positif dari siswa.

Respon siswa diperoleh dengan menggunakan angket siswa yang diberikan pada akhir pertemuan setelah proses pembelajaran selesai. hal ini dapat dilihat dari hasil pengamatan $70 \%$ siswa menyatakan ya, sedangkan yang menyatakan tidak 30\% pada model MMP, dimana dari 14 orang siswa mendapat respon positif dengan persentase sebesar $70 \%$, sedangkan 6 orang siswa tidak mendapat respon positif dari siswa dengan persentase $30 \%$.

Berdasarkan kesimpulan penelitian ini, maka peneliti menyampaikan saran dimana untuk bagi guru sebaiknya menggunakan model MMP dalam pembelajaran matematika, dan sebaiknya guru selain berperan sebagai fasilitator juga memberikan penekanan materi terhadap siswa. Sedangkan bagi kepala sekolah hendaknya melaksanakan monitoring atau pembinaan pelaksanaan pembelajaran-pembelajaran yang inovatif seperti pembelajaran dengan model MMP pada guru-guru.

Sebaiknya kepala sekolah menambah referensi-referensi tentang model MMP sebagai bahan masukan bagi guru-guru. Serta bagi peneliti lain hendaknya lebih kritis dalam menghadapi masalah yang muncul dalam dunia pendidikan, khususnya dalam masalah pembelajaran sehingga hasil penelitian ini dapat dijadikan sebagai referensi dalam memberikan informasi tentang pelaksanaan pembelajaran dengan model MMP.

\section{DAFTAR PUSTAKa}

Afriansyah, E. A. (2016). The Use of Realistic Approach to Enhance Students' Mathematical Problem Solving Skills. International Conference on Elementary and Teacher Education ICETE.

Anugrahana, A. (2012). Pengaruh pembelajaran matematika dengan menggunakan pendekatan realistik terhadap aktivitas siswa dan hasil belajar siswa di sekolah dasar. DIDAKTIKA, 3(2).

Budianto. (2018). Peningkatan Hasil Belajar Siswa melalui Pendekatan Matematika Realistik pada Bilangan Pecahan. Mosharafa: Jurnal Pendidikan Matematika, 7(3), 413424.

Budiarti, V., \& Lestariningsih, L. (2018). Profil Penyelesaian Soal Trigonometri Ditinjau dari Kemampuan 
Matematika. Mosharafa: Jurnal Pendidikan Matematika, 7(2), 273284.

Erin, \& Maharani, E. (2018). Persepsi Mahasiswa Pendidikan Matematika terhadap Perkuliahan Online. Mosharafa: Jurnal Pendidikan Matematika, 7(3), 337-344.

Faturohman, I., \& Afriansyah, E. A. (2020). Peningkatan Kemampuan Berpikir Kreatif Matematis Siswa melalui Creative Problem Solving. Mosharafa: Jurnal Pendidikan Matematika, 9(1), 107-118.

Haloho, S. H. (2016). Analisis Kemampuan Pemecahan Masalah Ditinjau Dari Gaya Kognitif Siswa Pada Model Pembelajaran Missouri Mathematics Project (Doctoral dissertation, Universitas Negeri semarang).

Hamdi, A. S., \& Bahruddin, E. (2015). Metode penelitian kuantitatif aplikasi dalam pendidikan. Deepublish.

Kurniasari, V. H. D., \& Susanto, S. (2015). Penerapan Model Pembelajaran Missouri Mathematics Project Dalam Meningkatkan Aktivitas Siswa Dan Hasil Belajar Siswa Sub Pokok Bahasan Menggambar Grafik Fungsi Aljabar Sederhana Dan Fungsi Kuadrat Pada Siswa Kelas X Sma Negeri Balung Semester Ganjil Tahun. Pancaran Pendidikan, 4(2), 153-162.

Latifah, D., \& Madio, S. S. (2014). Meningkatkan Kemampuan Pemecahan Masalah Matematis Siswa Melalui Model Pembelajaran Missouri
Mathematics Project (MMP). Mosharafa: Jurnal Pendidikan Matematika, 5(3), 159-168.

Lestari, P., \& Rosdiana, R. (2018). Kemampuan Pemecahan Masalah Matematis Siswa melalui Model Pembelajaran Learning Cycle 7E dan Problem Based Learning. Mosharafa: Jurnal Pendidikan Matematika, 7(3), 425-432.

Lisnani, \& Asmaruddin, S. N. (2018). Desain Buku Ajar Matematika Bilingual Materi Bangun Datar Menggunakan Pendekatan PMRI Berkonteks Kebudayaan Lokal. Mosharafa: Jurnal Pendidikan Matematika, 7(3), 345-356.

Lubis, S. H. (2019). Efektivitas Kemampuan Berpikir Kritis Matematika Siswa Menggunakan Model Pembelajaran Kooperatif Tipe Jigsaw Di Kelas X Tav SMK Negeri 1 Batang Angkola. JURNAL MathEdu (Mathematic Education Journal), 2(1), 61-66.

Mubarok, D. M., \& Nanang. (2013). Perbedaan Kemampuan Pemecahan Masalah Matematik Antar Siswa yang Mendapatkan Pembelajaran Problem Based Learning (Pbl) dan Jigsaw. Mosharafa: Jurnal Pendidikan Matematika, 2(1), 1-12.

Murtiyasa, B. (2016). Isu-Isu Kunci dan Tren Penelitian Pendidikan Matematika. PROSIDING Konferensi Nasional Penelitian Matematika dan Pembelajarannya Universitas Muhammadiyah Surakarta. 
Nanang. (2012). Meningkatkan

Kemampuan Siswa Dalam Pemecahan

Masalah Matematik Melalui

Pendekatan Metakognitif. Mosharafa:

Jurnal Pendidikan Matematika, 1(1),

1-8.

Nasryah, C. E., \& Rahman, A. A. (2018).

Penerapan Model Pembelajaran

Kooperatif Tipe Student Teams

Achievement Division (STAD) Pada

Materi Bangun Datar Segi Empat Di

Kelas 5 Sd Negeri Inpres115495

Sisumut Kota Pinang. Bina Gogik:

Jurnal IImiah Pendidikan Guru Sekolah

Dasar, 3(1).

Nawi, M. (2012). Pengaruh Strategi Pembelajaran dan Kemampuan

Penalaran Formal Terhadap Hasil

Belajar Matematika Siswa Sekolah

Menengah Atas (SWASTA) Al Ulum

Medan (Doctoral dissertation,

UNIMED).

Nopendra, D. (2017). Upaya

Meningkatkan Hasil Belajar

Matematikamenggunakan Metode

Missouri Mathematic Project Pada

Siswa Smp Bina Satria Medan Tp

2016/2017 (Doctoral dissertation).

Nurjannah, N. (2019). Kemampuan

Pemecahan Masalah Matematika

Siswa Yang Diajar Dengan

Menerapkan Model Missouri

Mathematics Project Di SMP Negeri 9

Parepare (Doctoral dissertation,

UNIVERSITAS NEGERI MAKASSAR).

Nurmayanti, N., Miliyawati, B., \& Rahmah,

M. A. (2019). Peningkatan
Kemampuan Koneksi Matematis

Siswa Melalui Model MMP. In

Prosiding Seminar Nasional

Pendidikan Universitas Subang

(SENDINUSA), 1(1), pp. 60-67.

Pamungkas, Y., \& Afriansyah, E. A. (2017).

Aptitude Treatment Interaction

terhadap Kemampuan Pemahaman

Matematis Siswa. Jurnal Pendidikan

Matematika RAFA, 3(1), 122-130.

Purwanti, S. (2015). Meningkatkan Kemampuan Komunikasi Dan Berpikir Kritis Matematis Siswa Sekolah Dasar Dengan Model Missouri Mathematics Project (MMP). Terampil: Jurnal Pendidikan dan Pembelajaran Dasar, 2(2), 253-266.

Rahman, A. A. (2018). Meningkatkan Prestasi Belajar Matematika Siswa Melalui Implementasi Contextual Teaching and Learning (Ctl) Berbantuan Alat Peraga Pada Siswa Kelas VIII SMP N 5 Meureubo. Genta Mulia: Jurnal IImiah Pendidikan, 9(2).

Rahman, A. A., \& Fauziana, F. (2018). Analisis Faktor Eksternal Penyebab Kesulitan Belajar Siswa SMP melalui Pembelajaran Scientific Approach. MAJU: Jurnal Ilmiah Pendidikan Matematika, 5(2).

Ridia, N. S. \& Afriansyah, E. A. (2019). Perbandingan Kemampuan Pemahaman Matematis Siswa melalui Auditory Intellectualy Repetition dan Student Teams Achievement Division. Mosharafa: Jurnal Pendidikan Matematika, 8(3), 515-526. 
Rukayah, R. (2012). Upaya Meningkatkan Hasil Belajar Peserta Didik Mata Pelajaran Matematika Kelas IV Semester II materi" Menyelesaikan Masalah yang Berkaitan dengan Pecahan" melalui Model Pembelajaran Contextual Teaching and Learning (CTL) di MI Bangunsari Kecamatan Pageruyung Kendal Tahun Pelajaran 2010/2011 (Doctoral dissertation, IAIN Walisongo).

Ruswana, A. M., \& Zamnah, L. N. (2018). Korelasi antara Self-Regulated Learning dengan Kemampuan Pemahaman Matematis Mahasiswa. Mosharafa: Jurnal Pendidikan Matematika, 7(3), 381-388.

Sudarsana, I. K. (2016). Peningkatan Mutu Pendidikan Luar Sekolah Dalam Upayapembangunan Sumber Daya Manusia. Jurnal Penjaminan Mutu, 1(1), 1-14.

Sundayana, R. (2012). Faktor-Faktor Yang Mempengaruhi Kemampuan Mahasiswa Dalam Praktikum Analisis Data Statistik. Mosharafa: Jurnal Pendidikan Matematika, 1(1), 35-42.

Suryati, S., Matsum, J. H., \& Asriati, N. (2016). Efektivitas Model Pembelajaran Group Investigation Berbantuan Media Power Point dalam Meningkatkan Hasil Belajar Siswa. Jurnal Pendidikan dan Pembelajaran UNTAN, 5(2).

Wijaya, E. Y., Sudjimat, D. A., Nyoto, A., \& Malang, U. N. (2016). Transformasi pendidikan abad 21 sebagai tuntutan pengembangan sumber daya manusia di era global. In Prosiding Seminar Nasional Pendidikan Matematika, 1 (26), 263-278.

Winarti, W., \& Haq, C. N. (2013). Perbedaan Hasil Belajar Matematika Siswa antara yang Mendapatkan Model Pembelajaran Brain Based Learning dengan Numbered Head Together. Mosharafa: Jurnal Pendidikan Matematika, 2(1), 65-76.

Yantri, I. D. (2017). Pengembangan Lembar Aktivitas Siswa Berbasis Model Missouri Mathematics Project Untuk Memfasilitasi Pemahaman Konsep Matematis Siswa Madrasah Tsanawiyah Di Pekanbaru (Doctoral dissertation, UIN Sultan Syarif Kasim Riau).

\section{Riwayat Hidup PenUlis}

Arief Aulia Rahman, M. Pd.

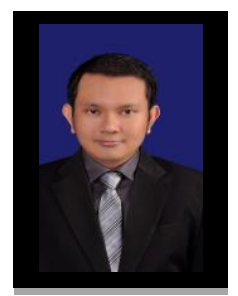

Lahir di Langsa, 11 Oktober 1991. Dosen di STKIP Bina Bangsa Meulaboh. Studi S1 Pendidikan Matematika Universitas Muhammadiyah Sumatera Utara, Medan, lulus tahun 2013; S2 Pendidikan Matematika universitas Negeri Medan, Medan, lulus tahun 2016.

\section{Cut Eva Nasryah, M.Pd.}

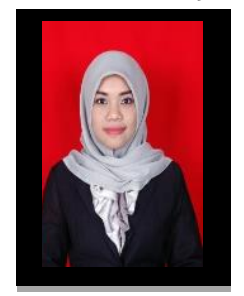
Lahir di Medan, 11 Januari 1992. Dosen di STKIP Bina Bangsa Meulaboh. Studi S1 Pendidikan Matematika Universitas Negeri Medan, Medan, lulus tahun 2014; S2 Pendidikan Matematika universitas Negeri Medan, Medan, lulus tahun 2017. 